\title{
University of Groningen
}

\section{Theoretical study on hydrogenation catalysts containing a metal hydride as additional hydrogen supply}

Snijder, E.D.; Versteeg, G.F.; Swaaij, W.P.M. van

Published in:

Chemical Engineering Science

DOI:

10.1016/0009-2509(92)85101-G

IMPORTANT NOTE: You are advised to consult the publisher's version (publisher's PDF) if you wish to cite from it. Please check the document version below.

Document Version

Publisher's PDF, also known as Version of record

Publication date:

1992

Link to publication in University of Groningen/UMCG research database

Citation for published version (APA):

Snijder, E. D., Versteeg, G. F., \& Swaaij, W. P. M. V. (1992). Theoretical study on hydrogenation catalysts containing a metal hydride as additional hydrogen supply. Chemical Engineering Science, 47(13), 38093816. https://doi.org/10.1016/0009-2509(92)85101-G

\section{Copyright}

Other than for strictly personal use, it is not permitted to download or to forward/distribute the text or part of it without the consent of the author(s) and/or copyright holder(s), unless the work is under an open content license (like Creative Commons).

The publication may also be distributed here under the terms of Article $25 f a$ of the Dutch Copyright Act, indicated by the "Taverne" license. More information can be found on the University of Groningen website: https://www.rug.nl/library/open-access/self-archiving-pure/taverneamendment. 


\title{
THEORETICAL STUDY ON HYDROGENATION CATALYSTS CONTAINING A METAL HYDRIDE AS ADDITIONAL HYDROGEN SUPPLY
}

\author{
E.D. SNIJDER, G.F. VERSTEEG and W.P.M. van SWAAIJ \\ Twente University of Technology, Department of Chemical Engineering \\ PO Box 217, 7500 AE Enschede, The Netherlands
}

\begin{abstract}
A hypothetical hydrogenation catalyst consisting of porous, catalytically active particles embedded with metal hydride powder was evaluated. The metal hydride provides temporarily additional hydrogen if the mass transfer rate of the hydrogen to the internal of the particle is not sufficient. A numerical model was developed to describe the hydrogenation of components in the liquid phase of a batch reactor. With this model two different reaction schemes were simulated. The first showed that the average hydrogen concentration increases with a metal hydride inside the catalyst particles. A reduction of byproduct formation and an increase in selectivity could be realized. The next system was the hydrogenation of succinonitril. Undesired products are oligomers and cyclic compounds, which are formed in the centre of the particle in the absence of hydrogen. The formation of these products is suppressed when a metal hydride is present. Another advantage is that the process can now be operated under more favorable conditions (lower pressure and higher initial succinonitril concentration) without significantly affecting the selectivities and byproduct formation.
\end{abstract}

\section{KEYWORDS}

Batch reactor; catalyst; hydrogenation; metal hydrides; modelling; selectivity.

\section{INTRODUCTION}

The last few decades a number of metal alloys (e.g. FeTi, $\mathrm{Mg}_{2} \mathrm{Ni}$ and $\mathrm{LaNi}_{5} \mathrm{Y} \mathrm{Y}_{\mathrm{x}}$ with $\mathrm{Y}=\mathrm{Al}, \mathrm{Cu}, \mathrm{Fe}, \mathrm{Ti}$ etc.) have been discovered which are able to absorb large amounts of hydrogen reversibly by forming ternary metal hydrides. Many applications are based on the ability of hydride formation. The alloys can be employed in hydrogen storage units (Snape and Lynch, 1980) and in heat pumps (van Mal and Miedema, 1978). When these materials are suspended in an inert liquid, it is possible to use them in a continuous hydrogen recovery process, as was shown by Holstvoogd et al. (1989). Metal hydrides are also active as hydrogenation or dehydrogenation catalysts (e.g. Soga et al., 1979, Imamoto et al., 1987 and Imamura et al., 1986). They recognized that metal hydrides do not only catalyze the reactions, but also supply the required hydrogen. A survey on metal hydride properties is given by e.g. Reilly et al. (1977).

Generally, metal hydrides are massive particles and have a small surface area as compared to porous industrial catalysts like Raney nickel or palladium on a carrier. When a fast reaction is carried out in a porous catalyst, the concentration of hydrogen can be very low in the centre of the particle and in some processes undesired side reactions become more important at a low hydrogen concentration. Combining the storage capacity of metal hydrides with the high activity of porous catalysts seems therefore very advantageous. In the present study a metal hydride is employed as hydrogen carrier inside porous catalyst particles. The particle itself contains active sites for the hydrogenation reaction, the provision of extra hydrogen by the hydride takes place if the mass transfer rate of hydrogen is not sufficient. In this study no attention was paid to the actual preparation of the catalyst. It was 
assumed that catalyst particles with a diameter of $3 \mathrm{~mm}$ can be prepared, containing 10 volume percent homogeneously distributed metal hydride powder. A batch reactor has been simulated with such type of catalyst particles and the influence of the metal hydride has been cvaluated.

\section{MODEL DESCRIPTION}

The model description for a batch reactor include the following phenomena:

- mass transfer from the gas to the liquid phase (only hydrogen) and from the liquid to the catalyst particles;

- diffusion inside the particles according to Fick's law.

If it is assumed that:

- the gas phase mass transfer resistance of hydrogen can be neglected;

- the slurry (both liquid and solids) is ideally mixed and the reactor is isothermal;

- Henry's law can be applied to calculate the hydrogen concentration at the gas/liquid interface;

- all catalyst particles are identical and perfectly spherical;

- the catalytic activity of the metal hydrides can be neglected when compared with the porous catalyst, the mass balances (macro) for component $i$ and hydrogen in the liquid bulk with concentration $\mathrm{C}_{\mathrm{i}}$ and $\mathrm{C}_{\mathrm{H}_{2}}$, respectively, can be written as:

$$
\begin{aligned}
& \frac{d C_{i}}{d t}=-k_{s, i} a_{s}\left(C_{i}-C_{i}(R)\right) \\
& \frac{d C_{H_{2}}}{d t}=-k_{s, H_{2}} a_{s}\left(C_{H_{2}}-C_{H_{2}}(R)\right)+k_{1} a\left(m_{H_{2}} C_{g, H_{2}}-C_{H_{2}}\right)
\end{aligned}
$$

The concentration on the outer surface of the particles $C_{i}(R)$ can be found by solving these equations simultaneously with mass balances (micro) for the particles, e.g., for a spherical particle:

$$
\varepsilon_{c} \frac{\partial C_{i}(r)}{\partial t}=D_{i, e f f} \frac{1}{r^{2}} \frac{\partial}{\partial r}\left(r^{2} \frac{\partial C_{i}(r)}{\partial r}\right)+R_{i}
$$

The macro and micro balances for each component are coupled with the condition that the molar flux to the boundary of the particle should be identical to the flux into the particle:

$$
k_{s, i}\left(C_{i}-C_{i}(R)\right)=I D_{i, e f f} \frac{\partial C_{i}(r)}{\partial r} I_{r=R}
$$

Besides the hydrogen consumption terms, the reaction rate $\mathrm{R}_{\mathrm{H}_{2}}$ also contains an additional term which accounts for the amount of hydrogen that is absorbed or desorbed by the hydride. Desorption takes place until the hydride is empty and therefore an instationary balance is required for the amount of hydrogen inside the metal hydride particles:

$$
\varepsilon_{\text {hydt }} \frac{d C_{H_{2}, \text { hydr }}(r)}{d t}=-k_{\text {hydr }}\left(C_{H_{2} / q}-C_{H_{2}}(r)\right) \varepsilon_{c}
$$

Instead of the hydrogen concentration in the hydride $\left(\mathrm{C}_{\mathrm{H}_{2}, \text { hydr }}\right)$, the hydride capacity $\mathrm{F}$ is used. Substitution in eqn. 5 gives:

$$
\frac{\varepsilon_{\text {hyd }} P_{\text {hydr }}}{2 M_{h y d r}} \frac{d F}{d t}=-k_{\text {hydr }}\left(C_{H_{2}, q q}-C_{H_{2}}(r)\right) \varepsilon_{c}
$$

The rate constant $k_{h y d r}$ is a function of $F$. When the hydride is fully loaded, $k_{h y d r}$ is zero as long as the hydrogen concentration is above the equilibrium concentration (no more absorption can take place). The $\mathbf{k}_{\text {hydr }}$ also becomes zero when capacity is zero. Mathematically this can be expressed as:

$$
\begin{array}{lll}
k_{\text {hydr }}=0 & \text { when } F=0 & \text { and } \mathrm{C}_{\mathrm{H}_{2}}<\mathrm{C}_{\mathrm{H}_{2, e q}} \\
& \text { when } \mathrm{F}=\mathrm{F}_{\max } & \text { and } \mathrm{C}_{\mathrm{H}_{2}}>\mathrm{C}_{\mathrm{H}_{2, e q}}
\end{array}
$$

The boundary conditions for the differential equations are: 


$$
\begin{aligned}
& t=0 \quad C_{A}=C_{A, 0} \quad C_{A}(r)=0 \\
& \mathbf{C}_{\mathbf{H}_{2}}=\mathrm{C}_{\mathrm{H}_{2}}(\mathbf{r})=m \mathbf{C}_{\mathrm{H}_{2}, \mathrm{gas}} \quad \mathrm{F}(\mathbf{r})=\mathrm{F}_{\max } \\
& C_{i}=C_{i}(r)=0 \\
& r=0 \quad \frac{\partial C_{i}(r)}{\partial r}=0 \quad r=R \quad k_{k, i}\left(C_{i}-C_{i}(R)\right)=\left.I D_{i, c f t} \frac{\partial C_{i}(r)}{\partial r}\right|_{r=R}
\end{aligned}
$$

This set of equations has been solved numerically with a similar method as presented by Cornelisse el al. (1980).

\section{RESULTS}

\section{Introduction and Parameter Choice}

With the presented model two reaction schenes were simulated: a simple reaction system with two parallel reactions and the hydrogenation of succinonitril. The effect of metal hydrides in the catalyst particles was evaluated by comparing the maximum achievable selectivity with and without the use of a hydride (at about $99.9 \%$ conversion). The conversion of reactant $A$ and selectivity of product $i$ are defined as:

$$
\zeta_{A}=\frac{n_{A, 0}-n_{A}}{n_{A, 0}} \quad \sigma_{i}=\left(\frac{v_{A}}{v_{i}}\right)\left(\frac{n_{i}-n_{i, 0}}{n_{A, 0}-n_{A}}\right)
$$

where $n$ is the sum of the total number of moles in the liquid bulk and in the pores of the catalyst particles. In order to be able to solve the reactor model, a number of parameters is required:

\begin{tabular}{|c|c|c|}
\hline & value in the simulations & sounce \\
\hline $\begin{array}{l}\text { reactor } \\
\text { variables }\end{array}$ & $\begin{array}{l}\varepsilon_{j}=0.3 \\
k_{1}=0.21 k \\
k_{k, 4} \text { with } \operatorname{Sh}=10\end{array}$ & $\begin{array}{l}\text { rough value } \\
\text { rough value: } \\
\text { rough value. }\end{array}$ \\
\hline $\begin{array}{l}\text { motel hydride } \\
\text { persmeters }\end{array}$ & $\begin{array}{l}G_{\text {gyt }}=0.1 \\
k_{\text {hydt }}=11 \mathrm{k} \\
P_{\text {hydr }}=8000 \mathrm{~kg} / \mathrm{m}^{3} \\
\ln \left(P_{\text {aq }}\right)=\frac{31300}{R T}-\frac{111.3}{R}\end{array}$ & $\begin{array}{l}\text { rough value } \\
\text { Hotutvoogd of al. (1989) } \\
\text { LaNi, own } \\
\text { meas urement }\end{array}$ \\
\hline
\end{tabular}

$$
\begin{array}{ll}
\text { - reactor variables }\left(\varepsilon_{s}, k_{s, i}, k_{1} a\right) & \text { - metal hyd ride parameters }\left(\varepsilon_{h y d r}, k_{h y d r}, P_{h y d r}, P_{e q}\right) \\
\text { - physical constants }\left(D_{i}, m_{H_{2}}\right) & \text { - catalyst variables }\left(\varepsilon_{c}, \tau \text {, rate constants, } d_{p}\right) \\
\text { - process variables }\left(P_{H_{2}}, T_{r}, C_{A, 0}\right) &
\end{array}
$$

\begin{tabular}{|c|c|c|}
\hline \multirow{2}{*}{ Phycical } & \multicolumn{2}{|c|}{$D_{\lambda}=D_{P}=D_{X}=5.10^{-9} \mathrm{~m}^{2} h$} \\
\hline & $\mathrm{q}_{\mathrm{h}_{2}}=1.10^{-6} \mathrm{~m}^{2} \mathrm{k}$ & $m_{H_{2}}=0.1$ \\
\hline \multirow{2}{*}{$\begin{array}{l}\text { kinctic } \\
\text { purameders }\end{array}$} & $k_{1}=1.10^{-3} \mathrm{~m}^{3} / \mathrm{mol} . \mathrm{s}$ & $k_{2}=1.10^{-3} 1 \mathrm{k}$ \\
\hline & $\varepsilon_{c}=0.5 \quad \tau=2.5$ & $d_{p}=3 \mathrm{mmn}$ \\
\hline process & \multirow{2}{*}{\multicolumn{2}{|c|}{$\begin{array}{l}P_{\mathrm{H}_{2}}=30 \mathrm{bur} \\
C_{A_{1,0}}=1000 \mathrm{molm}^{3} \\
C_{\mathrm{H}_{2}, 0}=96.7 \mathrm{molm}^{3}\end{array}$}} \\
\hline & & \\
\hline
\end{tabular}

Table 1 lists the reactor variables (set to a fixed value) and metal hydride parameters.

Table 1. Reactor and metal hydride parameters
Table 2. Model parameters for the simple reaction system

\section{Simple Reaction System}

The reaction scheme which was first studied consists of two parallel reactions: $A+H_{2} \rightarrow P$ and $A \rightarrow 1 / 2 X$. The first reaction is first order both in reactant $A$ and hydrogen, whereas the second reaction is first order in $A$ and zeroth order in hydrogen. The physical constants, kinetic parameters and process variables are listed in Table 2. Although typical for hydrogenation reactions, these constants do not refer to a real system, they are chosen to illustrate the effect of a metal hydride on the formation of the two products $P$ and $X$. Figure 1 gives concentration profiles for all components in the particle at $t=6$ minutes, $1 \mathrm{a}$ without and $1 \mathrm{~b}$ with $\mathrm{LaNi}_{5}\left(\mathrm{P}_{\text {eq }}=27.5\right.$ bar at $\left.373 \mathrm{~K}\right)$. 

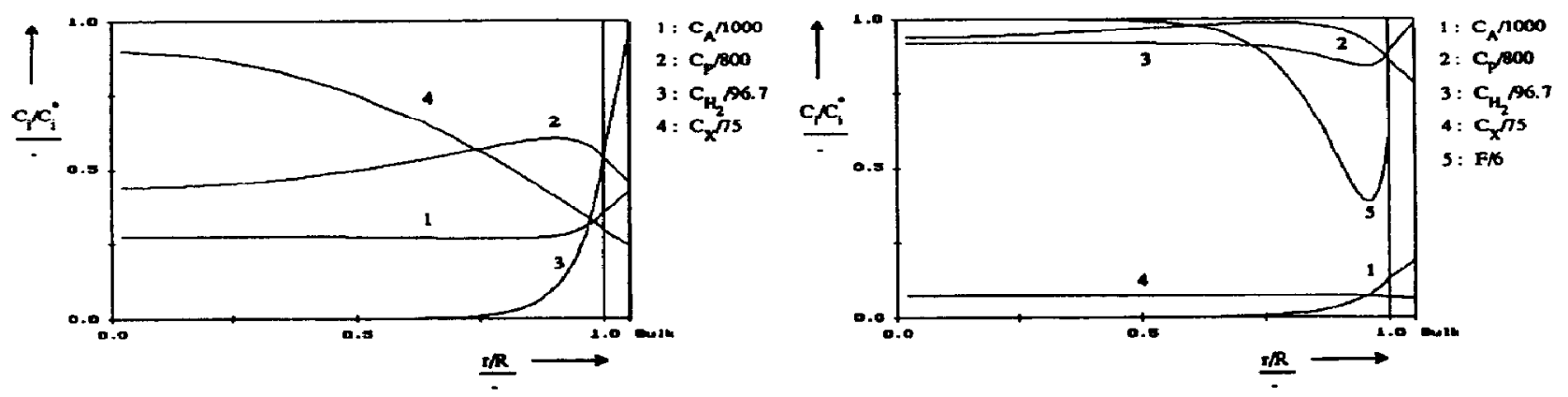

Fig. 1a and $1 \mathrm{~b}$. Concentration profiles in the particle for the simple system.

Without the metal hydride the concentration of hydrogen is zero in the centre of the particle during a period where the conversion of A changes from about 15 to $75 \%$. Since in that period the hydrogen concentration is below the hydrogen equilibrium concentration $\left(\mathrm{C}_{2}, e q\right)$ of the metal hydride, the hydride is able to provide additional hydrogen, resulting in an increased hydrogen concentration. With the conventional catalyst (without LaNis), a considerable amount of $\mathbf{X}$ is produced in the centre of the particle as long as the hydrogen concentration approaches a value zero. This is demonstrated by plotting the concentration of $\mathbf{X}$ versus time at three different locations in the catalyst particle, again without and with LaNi5 (Fig. 2a and 2b).
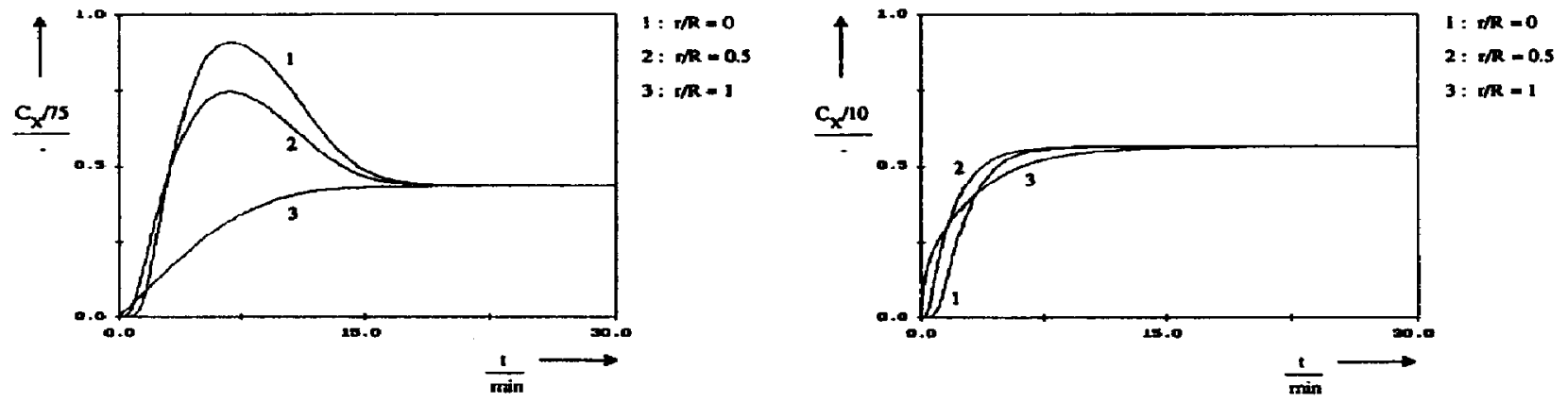

Fig. 2a and $2 b$. Concentration profiles of $X$ at different $r / R$ for the simple system.

Since the selectivities are directly influenced by the hydrogen concentration, it is to be expected that a higher equilibrium pressure of the metal hydride and consequently a higher average hydrogen concentration will give a higher selectivity towards product $P$. Figure 3 shows the influence of the equilibrium pressure on the selectivity towards both products. Indeed a selectivity increase from 92.1 to $98.6 \%$ for $P$ can be achieved if LaNis is used in the catalyst particle.

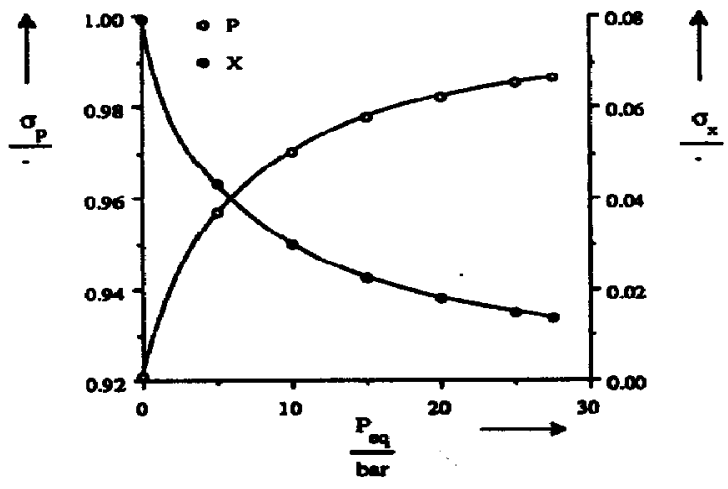

Fig. 3. Overall selectivities towards $P$ and $X$ at several equilibrium pressures.

From these simulations can be concluded that in this system the metal hydride desorbs hydrogen during most of the 
conversion of $\mathrm{A}$, resulting in a higher average hydrogen concentration. This has an influence on the selectivity towards $P$ (increased). Although the effect is dependent on the choice of the kinetic constants and reactor and process variables, the principle will remain the same for comparable systems.

\section{Hydrogenation of Succinonitril}

The hydrogenation of dinitrils to diamines is of practical importance, since the diamines are used as monomer for the production of nylons. Especially the hydrogenation of adiponitril has been investigated extensively. The reaction is usually thought to proceed via intermediate, very reactive imines (Rylander, 1979). Mares et al. (1988) gave a complete reaction scheme, including the formation of several byproducts (Fig. 4). Byproducts formation can be kept low if a good catalyst and solvent are used (Rylander, 1979). It is thought that the dimers and higher oligomers accumulate to some extend in the calalyst particles where they eventually alter the catalyst surface and, by that, the kinetic properties. Much more undesired material is produced then. The effect a metal hydride has on this reaction system was again evaluated by simulations with and without a hydride in the catalyst particles. First, a brief formulation of the kinetic expressions is given.

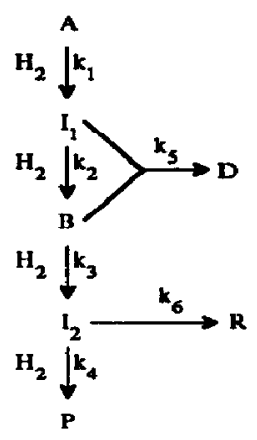

$$
\begin{aligned}
& \left.A: \mathrm{NC}_{2} \mathrm{CH}_{2}\right)_{2} \mathrm{CN} \\
& 1_{1}: \mathrm{HN}=\mathrm{CH}\left(\mathrm{CH}_{2}\right)_{2} \mathrm{CN} \\
& \text { B : } \mathrm{H}_{2} \mathrm{~N}\left(\mathrm{CH}_{2}\right)_{3} \mathrm{CN} \\
& \mathrm{I}_{2}: \mathrm{H}_{2} \mathrm{~N}\left(\mathrm{CH}_{2}\right)_{3} \mathrm{CH}=\mathrm{NH} \\
& \mathrm{P}: \mathrm{H}_{2} \mathrm{~N}\left(\mathrm{CH}_{2}\right)_{4} \mathrm{NH}_{2} \\
& \left.\mathrm{R}: \mathrm{CH}_{2}\right)_{3} \mathrm{CH}-\mathrm{NH}_{2} \\
& \text { D : HN } \\
& \underbrace{\mathrm{CH}-\left(\mathrm{CH}_{2}\right)_{2}-\mathrm{CN}}_{\mathrm{NH}_{2}}
\end{aligned}
$$

Fig. 4. Reaction scheme for the succinonitril hydrogenation.

The hydrogenation of the imines in Fig. 4 is very fast as compared to the formation reaction of the imines, consequently, the rate of the reactions to $B$ and $P$ are limited by the first step. Applying a steady state approximation for the imines yields:

$$
\theta_{I_{1}}=\frac{k_{1} \theta_{A} \theta_{H_{2}}}{k_{2} \theta_{H_{2}}+k_{5} \theta_{B}} \quad \theta_{1_{2}}=\frac{k_{3} \theta_{B} \theta_{H_{2}}}{k_{4} \theta_{H_{2}}+k_{6}}
$$

The surface coverage $\theta_{i}$ was calculated according to a Langmuir-Hinshelwood relation, adsorption of $P, R$ and $D$ on the surface was assumed to be negligible. This gives for $\mathrm{A}$ :

$$
\theta_{A}=\frac{K_{A} C_{A}}{1+K_{A} C_{A}+K_{B} C_{B}+K_{H_{2}} \sqrt{ } C_{H_{2}}}
$$

Assuming that $k_{5} \theta_{B}<<k_{2} \theta_{H_{2}}$ and $k_{6}<<k_{4} \theta_{H_{2}}$ leads to the following reaction scheme and rate equations:

$$
\begin{aligned}
& A+2 H_{2} \rightarrow B \quad R=k_{1}^{*} \theta_{A} \theta_{H_{2}} \quad k_{1}^{*}=k_{1} \\
& B+2 H_{2} \rightarrow P \quad R=k_{2}^{*} \theta_{B} \theta_{H_{2}} \quad k_{2}^{*}=k_{3} \\
& B \quad \rightarrow R \quad R=k_{3}^{*} \theta_{B} \quad k_{3}^{*}=\frac{k_{3} k_{6}}{k_{4}} \\
& A+B \quad \rightarrow D \quad R=k_{4}^{*} \theta_{A} \theta_{B} \quad k_{4}^{*}=\frac{k_{1} k_{5}}{k_{2}}
\end{aligned}
$$


Using these kinetic expressions implies that the surface coverage is in equilibrium with the concentration just above the surface inside the pores. The physical and kinetic constants and the process variables which have been used for the simulations are listed in Table 3.

Table 3. Model parameters for the succinonitril hydrogenation

\begin{tabular}{|c|c|}
\hline $\begin{array}{l}\text { physical } \\
\text { contstants }\end{array}$ & $\begin{array}{l}\mathbb{D}_{A}=D_{B}=D_{P}=D_{R}=3.510^{-9} \mathrm{~m}^{2} / \mathrm{k} \\
\mathbb{P}_{\mathrm{H}_{2}}=1.10^{-6} \mathrm{~m}^{2} / \mathrm{k} \quad \mathrm{W}_{\mathrm{H}_{2}}=0.2 \\
\mathbb{D}_{\mathrm{b}}=1.810^{-5} \mathrm{~m}^{2} \mathrm{k}\end{array}$ \\
\hline Rindic & $\begin{array}{l}d_{p}=3 \mathrm{~mm} \\
c_{c}=0.5 \quad \tau=2.5\end{array}$ \\
\hline proceser & $\begin{array}{l}P_{\mathrm{H}_{2}}=150 \mathrm{ber} \quad T_{r}=333 \mathrm{~K} \\
C_{\mathrm{A}_{0} 0}=1000 \mathrm{molm}^{3} \\
C_{\mathrm{H}_{2}, 0}=967.4 \mathrm{molkm}^{3}\end{array}$ \\
\hline
\end{tabular}

Figure 5 shows that the hydrogen concentration is zero in the central part of the catalyst in the case without LaNis. With LaNis the hydrogen concentration remains on the equilibrium concentration, resulting in a suppression of the byproduct formation.
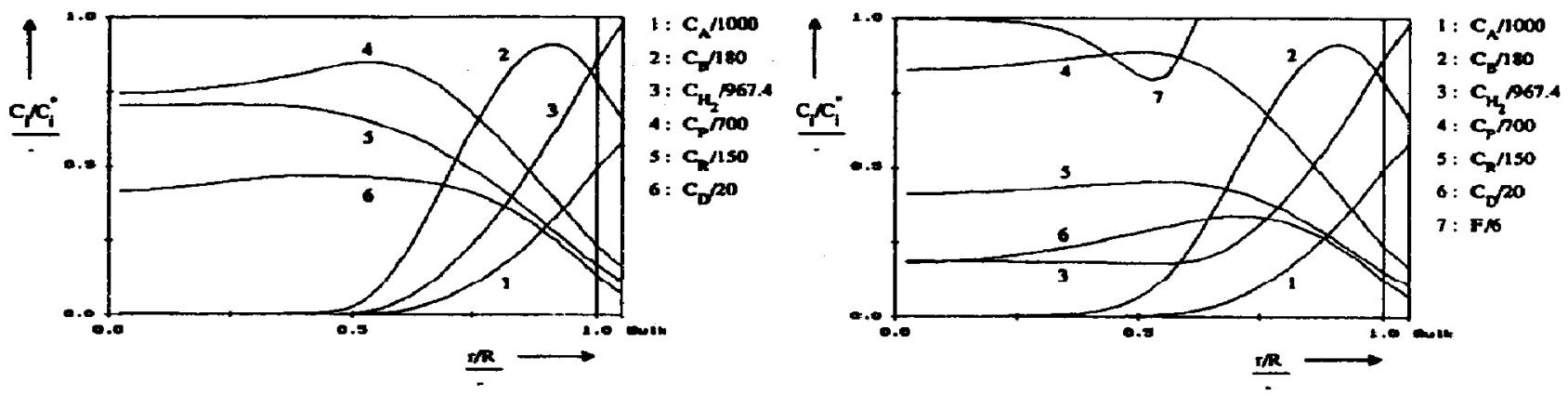

Fig. 5a and 5b. Concentration profiles in the particle for the succinonitril hydrogenation.

The effect of the equilibrium pressure on the maximum concentration of $R$ and $D$ is illustrated in Fig. 6, the overall selectivities appear to remain almost unchanged when a hydride is present in the catalyst particles.

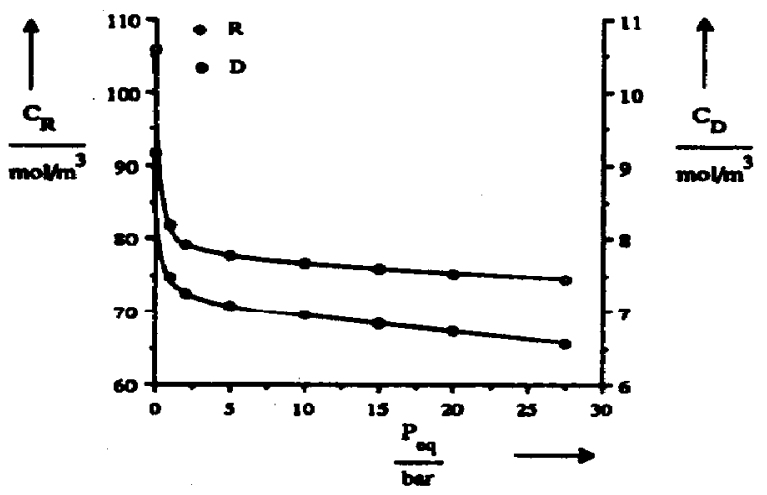

Fig. 6. Maximum achieved concentration of $R$ and $D$.

It is clear that the effect of a hydride in this reaction system is quite different from the previous system: a low equilibrium pressure already has a large influence on the maximum concentration of the byproducts, whereas the overall selectivities are almost unchanged. Moreover, increasing the equilibrium pressure above about 10 bar no longer decreases the byproduct formation significantly. 
These phenomena can be explained if the kinetics of this reaction scheme are examined. The ratio of the reaction rates from $B$ to $R$ and $P$ is only dependent on $\theta_{H_{2}}$ and is depicted in Fig. 7 for two different values of $C_{A}$ and $C_{B}$.

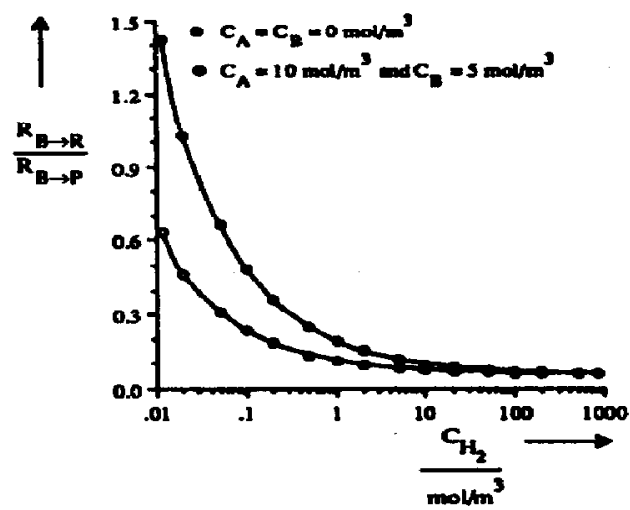

Fig. 7. $R_{B} \rightarrow R / R_{B} \rightarrow P$ at two locations in the particle.

In the centre of the particle both concentrations are almost zero, at $r / R=0.5$ they are about 10 and $5 \mathrm{~mol} / \mathrm{m} 3$ respectively. Only at very low hydrogen concentrations $\theta_{\mathrm{H}_{2}}$ becomes small, resulting in a sharp increase of $R_{B \rightarrow R} / R_{B \rightarrow P}$. At an equilibrium pressure of 1 bar the equilibrium concentration is $6.5 \mathrm{~mol} / \mathrm{m}^{3}$, the rate ratio is then already almost minimal $\left(=\mathrm{k}_{3}{ }^{*} / \mathrm{k}_{2}{ }^{*}\right.$ at $\left.\theta_{\mathrm{H}_{2}}=1\right)$. Increasing the equilibrium pressure above $10 \mathrm{bar}\left(\mathrm{C}_{\mathrm{H}_{2.09}}>65\right.$ mol $/ \mathbf{m}^{3}$ ) has no longer effect on $R_{B} \rightarrow R / R_{B} \rightarrow P$. This explains why using a metal hydride with a higher $P_{e q}$ hardly has any effect on the maximum concentration of $R$ and $D$.

The metal hydrides are active as additional hydrogen supply as long as $\mathrm{C}_{2}<\mathrm{C}_{2}$,eq. During that period the average hydrogen concentration is higher when a hydride is present in the catalyst particles. As the reaction proceeds, the transport rate of hydrogen into the particle is fast enough to meet with the demand for hydrogen and the hydrogen concentration increases again. However, the metal hydride starts to absorb hydrogen when $\mathrm{C}_{\mathrm{H}_{2}}>\mathrm{C}_{\mathrm{H}_{2} \text {,eq }}$ and the hydrogen concentration is still kept on $\mathrm{C}_{\mathrm{H}_{2} \text {,eq }}$ until the hydride is fully loaded. Obviously, the desorption followed by the absorption of the hydride averages completely in this case. There is overall almost no effect on the average hydrogen concentration nor on the overall selectivities.

The hydrogen pressure and initial succinonitril concentration which have been used for the simulations up until now can be found in industry. They are an optimum between operating costs, selectivity and reaction time. Increasing the initial succinonitril concentration or decreasing the hydrogen pressure would economically be attractive, but both cause a lower selectivity towards the desired product. Figure 8a gives the maximum concentrations of $R$ and $D$ at different hydrogen pressures both with and without LaNi5, whereas Fig. 8b depicts the influence of the initial concentration of $\mathbf{A}$.
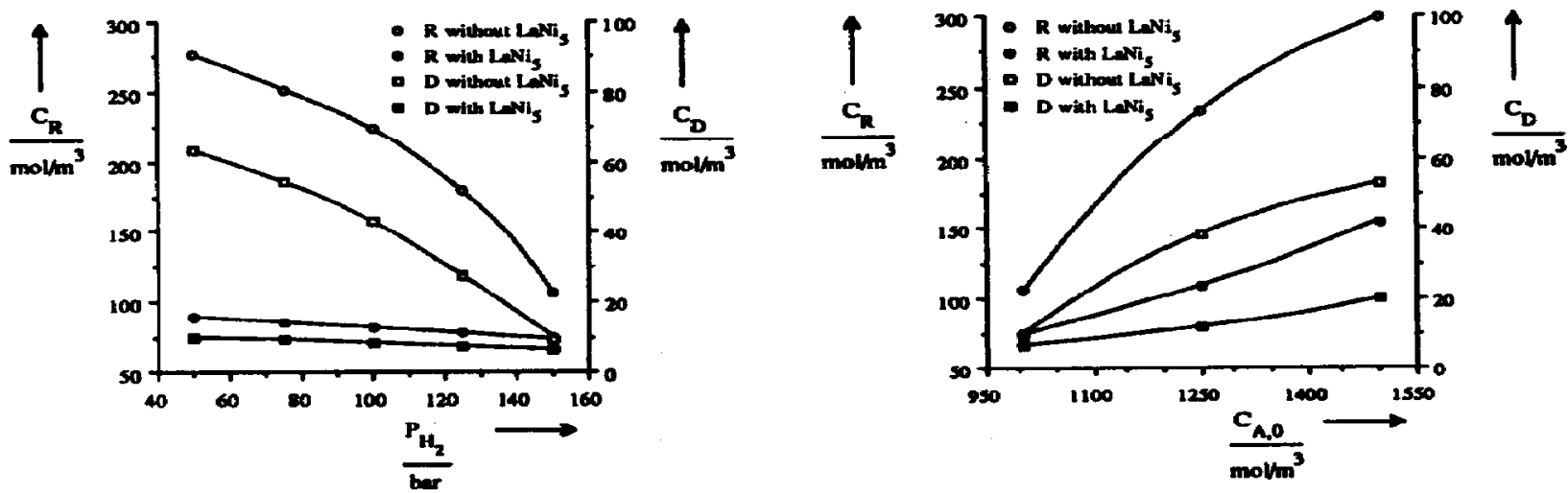

Fig. 8a and 8b. Maximum concentration of $R$ and $D$. a) $C_{A, 0}=1000 \mathrm{~mol} / \mathrm{m}^{3}$ b) $P_{H 2}=150$ bar 
Decreasing the pressure from 150 to 50 bar has a strong effect if the process is operated without LaNis, especially on the maximum concentrations of $R$ and $D$. With LaNis the selectivities remain almost unchanged, whereas the influence on the maximum concentrations is much smaller. Operating at pressure of 75 bar with LaNis yields almost the same selectivity and byproduct formation as at 150 bar without LaNis. The effect is less pronounced for suppressing the byproduct formation when the initial concentration of $A$ is increased. Still, with LaNis present, it is possible to run the process at a somewhat higher initial concentration without effecting the selectivities.

\section{CONCLUSIONS}

The simulations showed that the use of a metal hydride inside porous catalyst particles prevents hydrogen depletion in the centre of the catalyst particles. Consequently, the average hydrogen concentration is increased. With a reaction system consisting of two parallel reactions, which are both first order in reactant $A$ and first and zeroth order, respectively, in hydrogen, this resulted in a higher overall selectivity. The higher hydrogen concentration appeared to be advantageous for the succinonitril hydrogenation as well. It was found that the byproduct formation in the centre of the particle was suppressed, but with this system the overall selectivities remain almost unchanged if the process is operated under industrially optimal conditions. With a metal hydride inside the catalyst particles however, it turned out to be possible to operatethe process at 75 bar instead of 150 bar, while still the same selectivity could be achieved. Also a somewhat higher initial succinonitril concentration can be applied without a significant influence on the selectivities or byproduct formation. Under otherwise the same conditions, but in the absence of the metal hydride, a large increase in undesired product formation was found as well as a reduction in selectivity.

Acknowledgements- These investigations were supported by DSM and the Foundation for Chemical Research in the Netherlands (S.O.N.). We also acknowledge E.J. Brand for his contribution to the numerical work.

\section{NOTATION}

a specific gas liquid contact area

a specific solid area $\left(6 \varepsilon_{s} /\left(d_{p}\left(1-\varepsilon_{s}\right)\right)\right.$

F hydride capacity

$m_{H_{2}} \quad C_{H_{2}, 1} / C_{H_{2, g}}$ at equilibrium

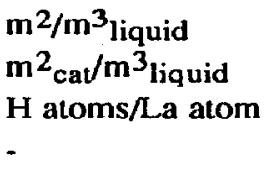

$\begin{array}{ll}\varepsilon_{\mathrm{c}} & \mathrm{V}_{\text {pores }} / \mathrm{V}_{\mathrm{c}} \\ \varepsilon_{\mathrm{hydr}} & \mathrm{V}_{\mathrm{hydr}} / \mathrm{V}_{\mathrm{c}} \\ \varepsilon_{\mathrm{s}} & \mathrm{V}_{\mathrm{d}} /\left(\mathrm{V}_{\mathrm{c}}+\mathrm{V}_{\mathrm{l}}\right) \\ \tau & \text { tortuosity }\end{array}$

$\mathrm{m}^{2}$ pores $/ \mathrm{m}^{3}$ cat

$\mathrm{m}^{2}$ hydride/ $\mathrm{m}^{3}$ cat

$\mathrm{m}^{2}$ cat $/ \mathrm{m}^{3}$ slurry

$\mathrm{ID}_{\mathrm{eff}}=(\varepsilon / \tau) \times \mathrm{ID}$

\section{REFERENCES}

Cornelisse, R., Beenackers, A.A.C.M., van Beckum, F.P.M. and van Swaaij, W.P.M. (1980). Numerical calculation of simultaneous mass transfer of two gases accompanied by complex reversible reactions. Chem. Eng. Sci. 35, 1245-1260.

Holstvoogd, R.D., van Swaaij, W.P.M., Versteeg, G.F. and Snijder, E.D. (1989). Continuous absorption of hydrogen in metal hydride slurries. Z. Phys. Chem. N.F. 164, 1429-1434.

Imamoto, T., Mita, T. and Yokoyama, M. (1987). Reduction of organic compounds with rare-earth intermetallics containing absorbed hydrogen. J. Org. Chem. 52, 5695-5699.

Imamura, H., Yamada, K., Nukui, K. and Tsuchiya, S. (1986). Dehydrogenation reactions of organic compounds using hydrogen-absorbing rare earth intermetallic compounds. $J$. Chem. Soc., Chem. Commun., 367-368.

Mal, H. H. van and Miedema, A.R. (1978). Some applications of LaNis-type hydrides. In: Hydrogen for Energy Storage (A.F. Andressen and A.J. Maeland, eds.), pp. 251-260. Pergamon, Oxford.

Mares, F., Galle, J.E., Diamond, S.E. and Regina, F.J. (1988). Preparation and characterization of a novel catalyst for the hydrogenation of dinitrils to aminonitrils. J. Catal. 112, 145-156.

Reilly, J.J. (1977). Metal hydrides as hydrogen storage media and their applications. In: Hydrogen, its technology and implications (Cox and Williamson, eds.), vol 2, pp. 13-48. CRC press, Cleveland.

Rylander, P.N. (1979). In: Catalytic hydrogenation in organic synthesis, pp. 138-152. Academic press, New York. Snape, E. and Lynch, F.E (1980). Metal hydrides make hydrogen accessible-I. ChemTech September, 578-583.

Soga, K., Imamura, H. and Ikeda, S. (1979). Hydrogenation of ethylene over some intermetallic compounds. $J$. Catal. 56, 119-126. 